\title{
Design Social: uma experiência de desenvolvimento de projetos a partir de demandas reais
}

Social Design: an experience of development of projects based on real demands

CORRÊA, Glaucinei Rodrigues ; Doutor; Escola de Arquitetura - UFMG

glaucinei@ufmg.br

\section{Resumo}

Este artigo apresenta os resultados de uma disciplina cujo objetivo foi estudar o Design Social e suas implicações. A partir de necessidades reais de dois grupos de Belo Horizonte - o Flores do Morro (que reúne mulheres assistidas por uma associação sem fins lucrativos, com a finalidade de exercer atividades de assistência social) e a Asmare (Associação de Catadores de Papel, Papelão e Material Reaproveitável) -, os alunos, com base na análise das demandas de ambos, escolheram um para propor projetos / soluções, tendo como referência o Design Social.

Palavras Chave: design social; questões sociais; autoestima.

\begin{abstract}
This article presents the results of a discipline that had as objective to study the Social Design and its implications. Based on the real needs of two groups in Belo Horizonte - Flores do Morro (that join women assisted by a non-profit association with the purpose of carrying out social assistance activities) and Asmare (Association of Paper, Material Re-useable) -, the students, based on the analysis of the demands of both, chose one to propose projects / solutions, having as reference the Social Design.
\end{abstract}

Keywords: social design; social questions; self-esteem. 


\title{
1 Introdução
}

O Design Social tem sido discutido por diversos autores ao longo dos últimos anos. Explica Araújo (2017, p. 19): "O entendimento desse conceito tem causado polêmica para uns, trazido conforto para outros e servido como motivação para outros tantos". Assim como ocorre com o design, de maneira geral, não há consenso sobre o termo, e talvez nunca haverá. Essa discussão e essa diferenciação no modo de se pensar e de se fazer design - neste caso, voltado para questões sociais - podem trazer contribuições significativas para a área.

Em relação à prática do design, há muitas formas e modos de ação / trabalho do designer, os quais têm mudado a maneira de se pensar e, principalmente, de se fazer design. Nesse sentido, torna-se relevante esclarecer de qual design se trata, pois, tratar o termo genericamente pode não ser o melhor caminho. Apenas para citar alguns exemplos, o design pode ser: industrial (em grandes ou médias quantidades ou em lotes), autoral (de autor ou de peças assinadas), de autoprodução (pequenos lotes ou peças numeradas), colaborativo (com a participação de usuários no processo de projeto). Essas maneiras de atuar podem ser encontradas separadas ou em conjunto. Por isso, entende-se que o mais adequado é tentar compreender o design no plural, ou seja, "designs", devido à variedade, pluralidade e diversidade de situações e possibilidades com as quais essa área pode ser exercida e aplicada.

Especificamente sobre Design Social, neste artigo toma-se como referência a abordagem feita por Araújo (2017):

\begin{abstract}
[...] Diferente daquele design para a produção industrial, em que as pessoas eram consumidoras, estamos tratando de um caminho que desconstrói a figura do consumidor apenas, coloca a pessoa como um usuário, no centro do processo de design, e conduz ao entendimento de um design feito com as pessoas, em coautoria. Um design que tira o foco do sistema econômico e produtivo vigente e coloca atenção no humano, com uma interação direta entre o designer e as pessoas evolvidas, a partir da qual o processo de projeto se desenvolve. 0 modo de ser, de estar, de agir, de se manifestar das pessoas, assim como os desejos, valores, intenções de pessoas e grupos e as interações humanas, desencadeiam o processo de projeto (ARAÚJO, 2017, p. 23, grifos nossos).
\end{abstract}

A partir dessa colocação, entende-se como Design Social o desenvolvimento de projetos a partir de três pressupostos: a) participação das pessoas ou grupo no processo de projeto - ou seja, o projeto não é "feito para" determinado grupo, e sim "feito com" as pessoas; b) geralmente destina-se a atender demandas de grupos - ou seja, questões sociais; e c) o foco está no processo e no atendimento das necessidades do grupo.

Visando aprofundar no assunto e propor alternativas para levar aos alunos questões relacionadas ao Design Social, ofertou-se uma disciplina para alunos do curso de graduação em Design da Universidade Federal de Minas Gerais (UFMG), no segundo semestre de 2017, semelhante ao apontado por Araújo (2017) - desenvolvimento de projetos a partir de observação do cotidiano -, para que pudessem estudar o assunto, pesquisar autores da área e propor o desenvolvimento prático de projetos tendo como referência necessidades reais. 


\section{Design para questões sociais: uma disciplina para entender o assunto e desenvolver projetos para o bem-estar social}

A disciplina teve por objetivos: estudar o Design Social e suas implicações; definir o papel do designer e sua responsabilidade na sociedade; promover o uso do processo de design, para contribuir com o bem-estar social; aplicar os conceitos de design, para levantar questões; e desenvolver projetos a partir de necessidades reais.

No âmbito das atividades da disciplina, os alunos puderam escolher um dos grupos - Flores do Morro e Associação de Catadores de Papel, Papelão e Material Reaproveitável (Asmare) - para o desenvolvimento dos projetos.

O grupo Flores do Morro reúne pessoas (principalmente mulheres) da comunidade do Aglomerado Morro das Pedras, localizado na zona oeste em Belo Horizonte - MG, que são assistidas semanalmente por funcionários da Cáritas Nossa Senhora de Fátima (associação sem fins lucrativos, fundada em 1964, cuja finalidade é exercer atividades de assistência social) e por voluntários. Nos encontros do grupo, são realizadas oficinas de artesanato, dança, teatro e demais modalidades artísticas, com a finalidade de promover a superação das diversas dificuldades enfrentadas por essas pessoas em suas vivências pessoais, conjugais e familiares. As atividades são mantidas com verba pública municipal repassada ao Caritas e doações. Porém, os recursos são escassos e passam longe de suprir todas as demandas do grupo.

A Asmare, fundada em 1990, surgiu em função do trabalho de mobilização e capacitação dos catadores, realizado pela Pastoral de Rua da Arquidiocese de Belo Horizonte, fruto de um intenso processo mobilizatório. Atende diretamente 180 associados e ex-moradores de rua em duas unidades (denominadas "galpões"), as quais apresentam diferenças tanto de infraestrutura quanto de relação dos associados / catadores com a instituição. O galpão principal que é maior, situa-se na região central de Belo Horizonte, na Avenida do Contorno, o qual recebe o material trazido pelos próprios catadores das ruas, os quais possuem pequenos espaços onde cada um realiza a triagem do próprio material e vende para a associação ao final da semana. $O$ segundo galpão, que se localiza mais afastado do Centro, na Rua Ituiutaba, recebe, principalmente, materiais em grande escala, vindos da prefeitura, por meio da coleta seletiva e de doações de empresas. Os catadores que lá trabalham realizam a triagem, sendo o lucro dividido igualmente entre eles no final da semana.

A disciplina foi organizada em quinze encontros semanais:

- Apresentação da disciplina, da metodologia adotada, dos critérios de avaliação etc.;

- Visita à Asmare e ao Flores do Morro, para os alunos conhecerem as atividades de cada um, o modo como funcionam e sobretudo, seus principais problemas;

- Quatro encontros / seminários orientados para a discussão de textos ${ }^{1}$ sobre Design Social, previamente selecionados pelo professor. Cada grupo de alunos ficou responsável por ler determinado texto e por apresentar as principais ideias, a biografia do autor e os pontos principais relacionados ao tema. A leitura e a reflexão desses textos foram fundamentais para o desenvolvimento dos projetos;

\footnotetext{
${ }^{1}$ Bonsiepe (2013); Celaschi, Moraes (2013); Costa (2009); Bergmann, Magalhães (2017); Silva et al. (2016); Margolin, Margolin (2004); e Kimbell, Julier (2012).
} 
- Um encontro para os grupos de alunos apresentarem as propostas de projeto;

- Nas seis semanas seguintes, os alunos trabalharam no desenvolvimento dos projetos com os grupos escolhidos. O horário da aula foi utilizado para orientações relacionadas ao desenvolvimento dos projetos;

- Encontro final, para apresentação dos projetos. Nesse dia, as mulheres do Flores do Morro e os catadores da Asmare foram convidados a participar da avaliação dos projetos.

\subsection{Propostas de projetos na disciplina}

Ao todo, foram cinco propostas. Três grupos de alunos escolheram desenvolver projetos com o Flores do Morro e dois com a Asmare.

As propostas para o Flores do Morro foram:

GRUPO 1 - Desenvolvimento da identidade cultural do grupo Flores do Morro, utilizando ferramentas de baixo custo. Explicam os próprios alunos: "Nosso trabalho foi buscar formas de se trabalhar a identidade cultural das criações do grupo Flores do Morro, utilizando ferramentas de baixo custo, ouvindo suas histórias e utilizando da grande vontade dessas mulheres de produzir".

GRUPO 2 - Aplicação da marca e desenvolvimento de um manual de técnicas. O manual para a aplicação da marca foi construído de forma colaborativa com as integrantes do Flores do Morro, com base no estudo das cores, das padronagens, dos conceitos e das referências criativas utilizadas pelo grupo. O manual de técnicas foi desenvolvido para reunir tanto técnicas já aplicadas no Flores do Morro quanto novas técnicas de artesanato.

GRUPO 3 - Projeto do ambiente no qual o grupo se encontrava para as atividades. O grupo desenvolveu a proposta de fazer uma reforma no espaço onde eram realizadas as atividades do grupo Flores do Morro, que é um salão da igreja do bairro, cedido pela paróquia. No final, fez propostas relacionadas à: interferência na iluminação, quadros com fotos das pessoas que participam das atividades e quadros com flores feitas por elas próprias.

As propostas de projeto para a Asmare foram:

GRUPO 4: Desenvolvimento de um kit composto por sacola de lixo personalizada e panfleto informativo a ser distribuído pelos próprios catadores da Asmare no trajeto que já percorrem diariamente para catação. De acordo com o grupo, os objetivos foram: informar à comunidade quanto à facilidade de separação do material reciclável e sua importância; criar empatia da comunidade com o catador e a causa (e vice-versa), por meio da aproximação de ambos; e aumentar o volume do material recolhido pelo catador, mantendo seu trajeto atual.

GRUPO 5 - Desenvolvimento de um aplicativo para telefone celular que pudesse divulgar o trabalho desenvolvido pela Asmare, explicar à população quanto à maneira correta de se fazer a separação do lixo doméstico e, sobretudo, conectar as pessoas e os catadores. Por meio desse recurso as pessoas poderiam agendar uma coleta diretamente com a Associação. Os usuários seriam as pessoas que querem fazer coleta, mas não sabem como proceder. Enfim, pessoas que precisam ser conscientizadas a fazerem a coleta seletiva.

Uma das propostas dos alunos, a do GRUPO 2, com o projeto do manual de técnicas para o 
Flores do Morro, merece ser apresentada em detalhe pelos resultados alcançados e por ter feito uma melhor apropriação dos conceitos relacionados ao Design Social durante o processo de desenvolvimento do projeto.

\section{Projeto de aplicação da marca e manual de técnicas para o Flores do Morro}

Os alunos ${ }^{2}$ realizaram seis encontros com o grupo Flores do Morro. No primeiro, denominado "conversa", a primeira atividade do grupo foi discutir e propor, juntamente com as participantes, um manual de aplicação da marca do grupo, desenvolvida por uma designer, mas sem instruções para aplicação. O grupo estabeleceu os limites mínimos para redução, área de preservação quando aplicada simultaneamente a outras marcas e exemplos de aplicações incorretas. Essas atividades foram feitas juntamente com as participantes e os alunos, por meio de experimentações com a impressão da marca em papel. Também, realizou-se uma roda de conversa para discutir com o grupo "Quem é o Flores do Morro?" e "Por que as pessoas frequentam esse lugar? Quais valores e sentimentos são despertados?"

Figura 1: Primeiro encontro dos alunos com os participantes do grupo Flores do Morro

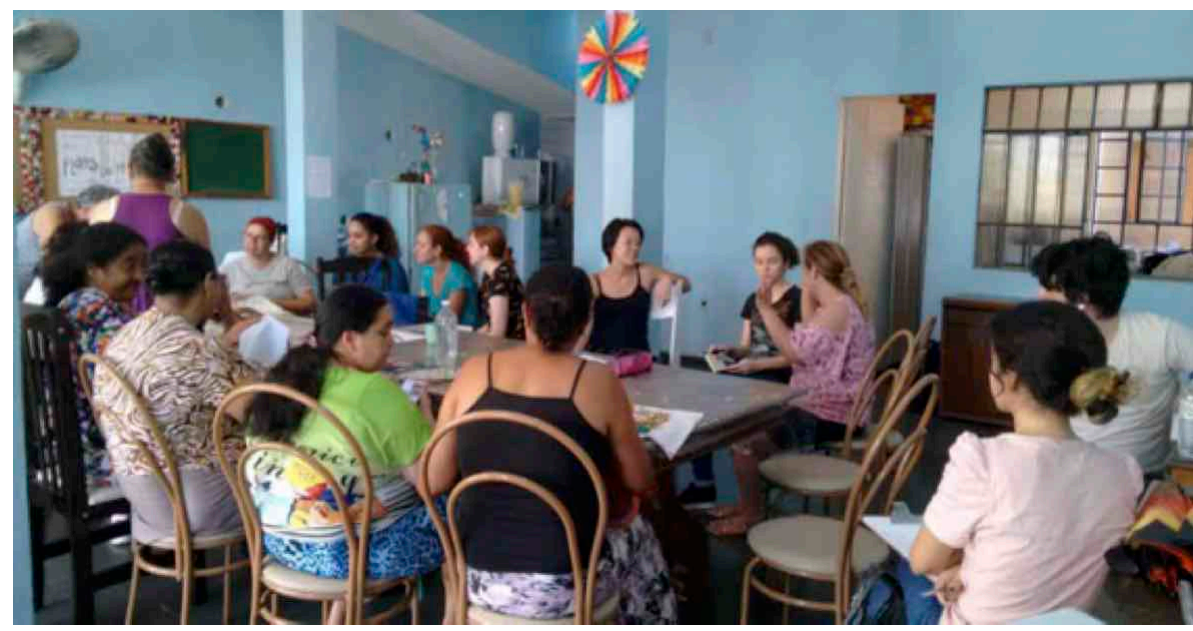

Fonte: Autor

O segundo encontro, relacionado à criação visual, teve por objetivo pensar nos elementos do bairro, por meio de uma visita a alguns pontos considerados importantes pelas mulheres, para descobrir formas, texturas, cores e histórias, que poderiam ser representativas e que gerassem a identificação das pessoas com o grupo. A partir dessas referências, elas fizeram desenhos que representavam esses locais. Além disso, os alunos apresentaram alternativas de produtos às participantes para a aplicação das técnicas.

\footnotetext{
2 Participaram deste projeto os seguintes alunos: Alessandro Policarpo, Camila Fialho, Cynthia Damaceno, Izan Machado, Jéssica Kawaguiski, Luísa Monteiro e Mércia Guilherme.
} 
Figura 2: Segundo encontro com tema de criação visual: buscando referências no bairro

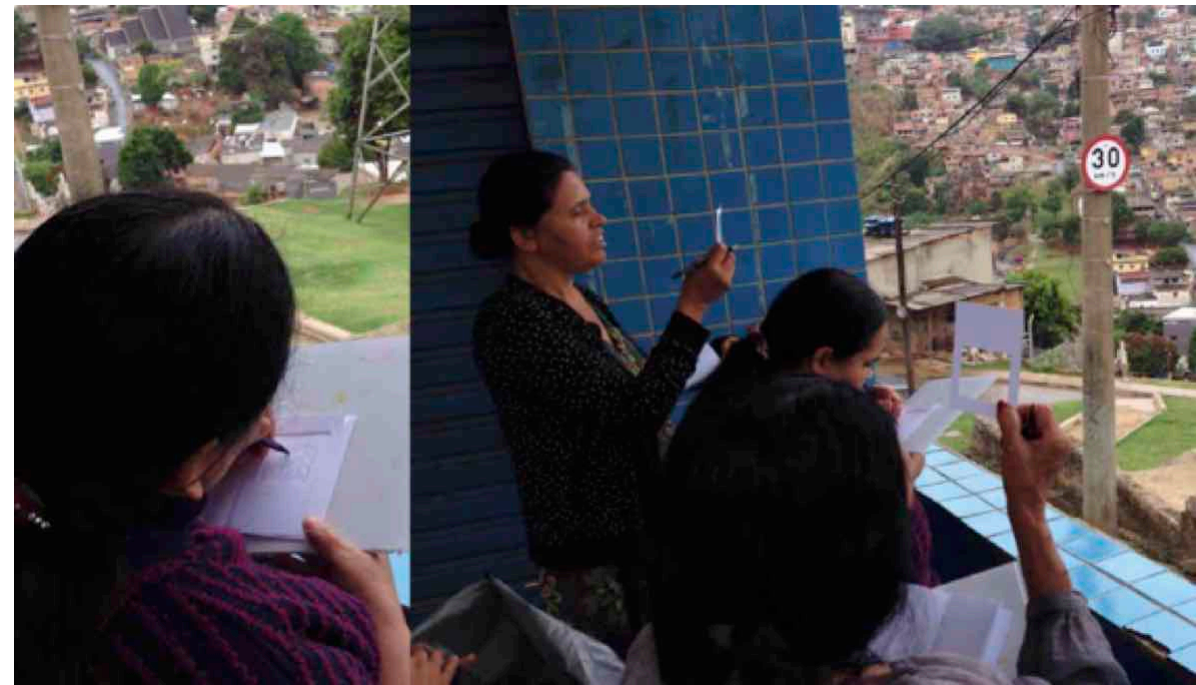

Fonte: Autor

Figura 3: Segundo encontro com tema de criação visual: apresentação de técnicas de papel machê e carimbo
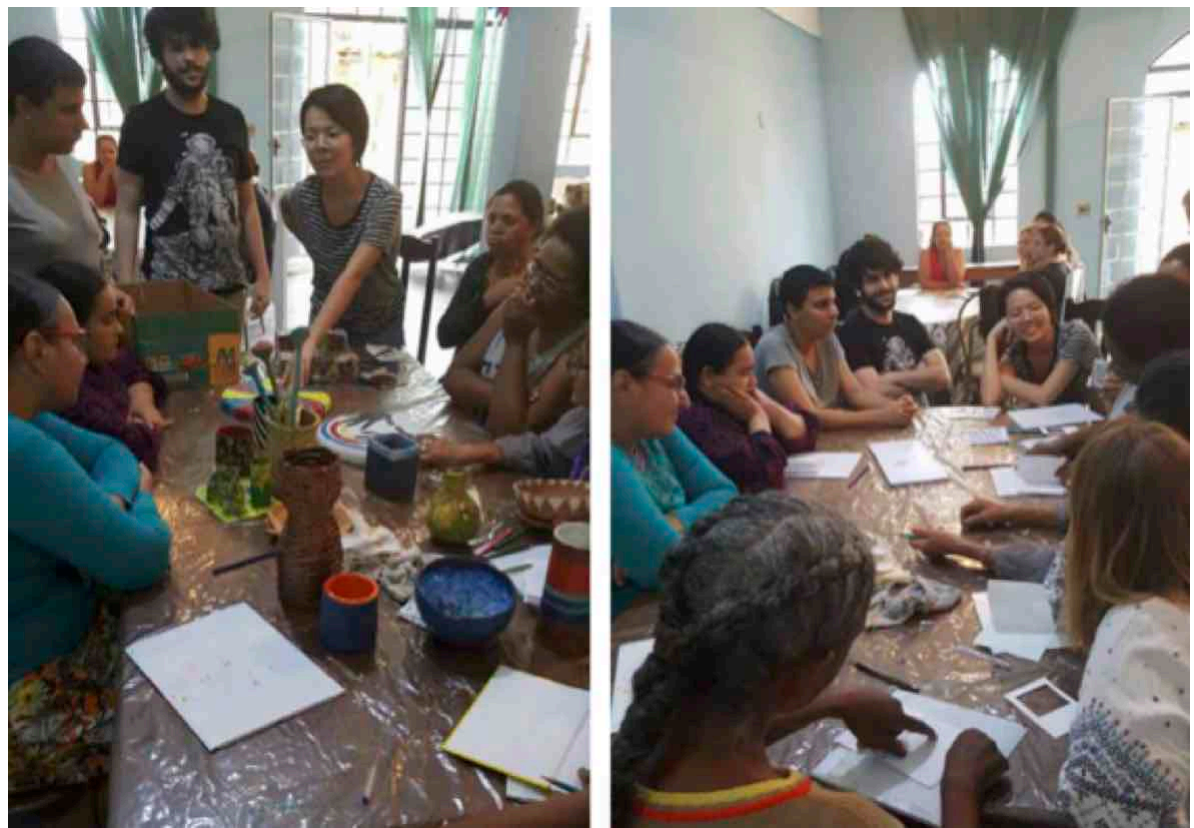

Fonte: Autor

O terceiro encontro teve por objetivo refinar e aprimorar os desenhos, introduzir e realizar experimentação das técnicas de carimbo, estêncil e papel machê. 
Figura 4: Experimentação da técnica de papel machê no terceiro encontro

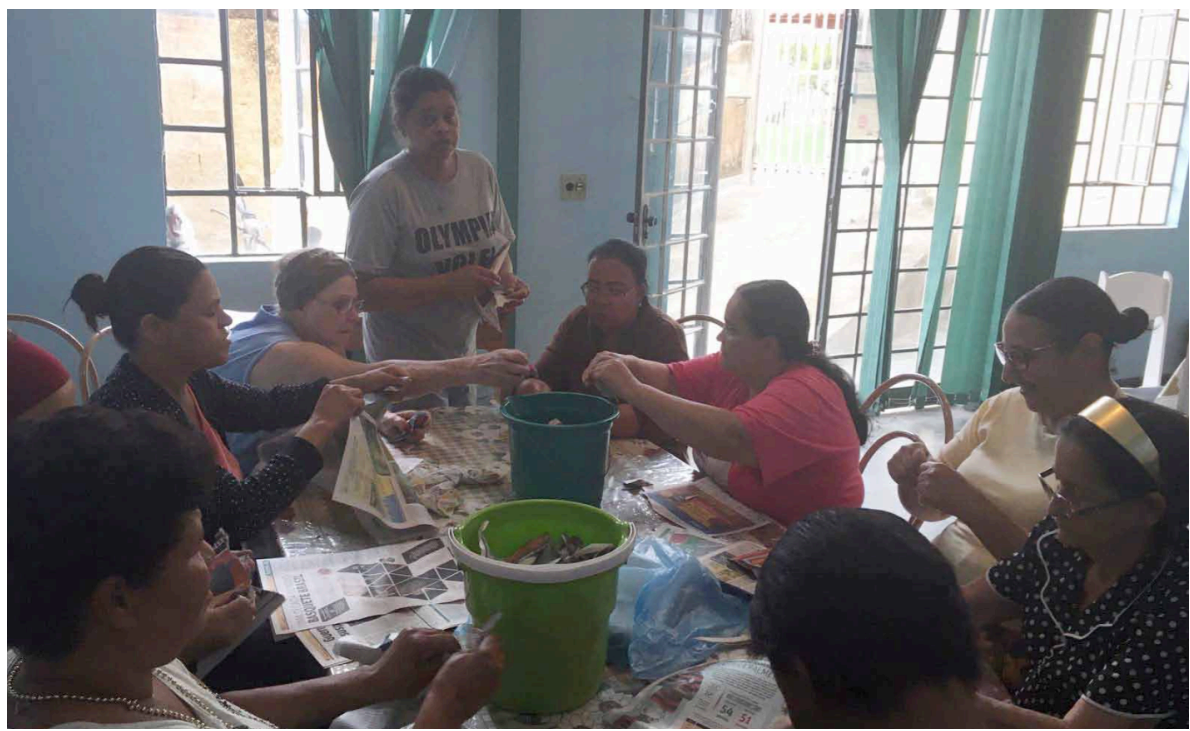

Fonte: Autor

Figura 5: Parte do resultado da experimentação da técnica de carimbo no terceiro encontro

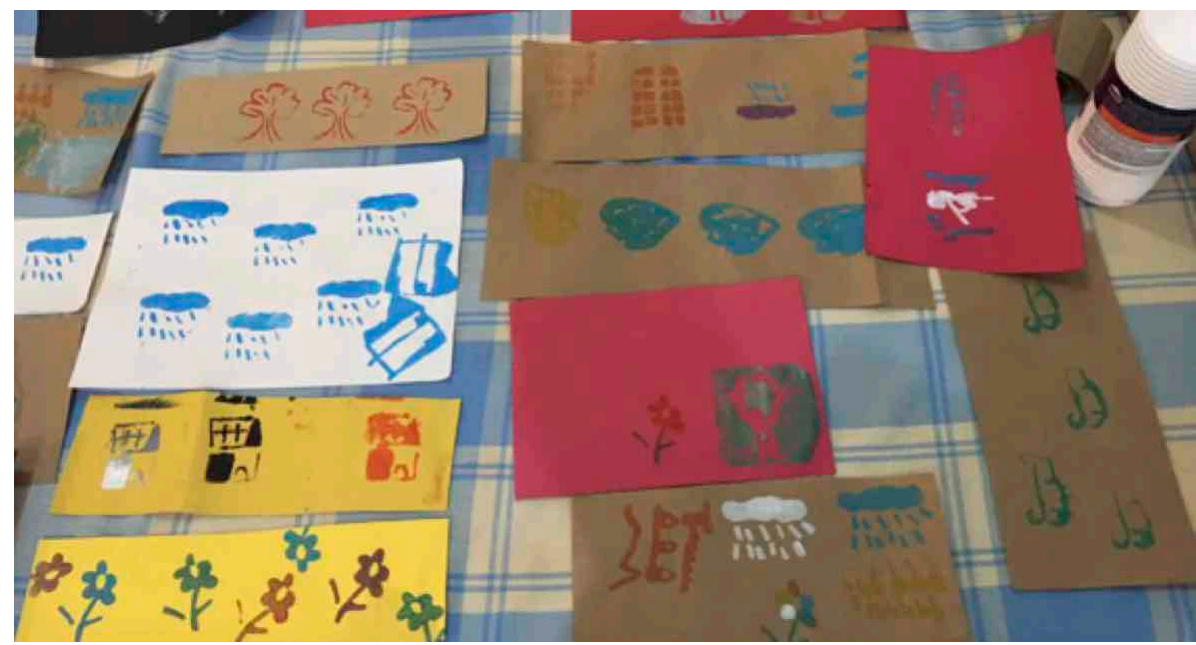

Fonte: Autor

O quarto encontro teve por objetivo aprofundar as técnicas: papel machê, estêncil e carimbo (Figura 6). 
Figura 6: Parte do resultado da experimentação da técnica de carimbo no terceiro encontro
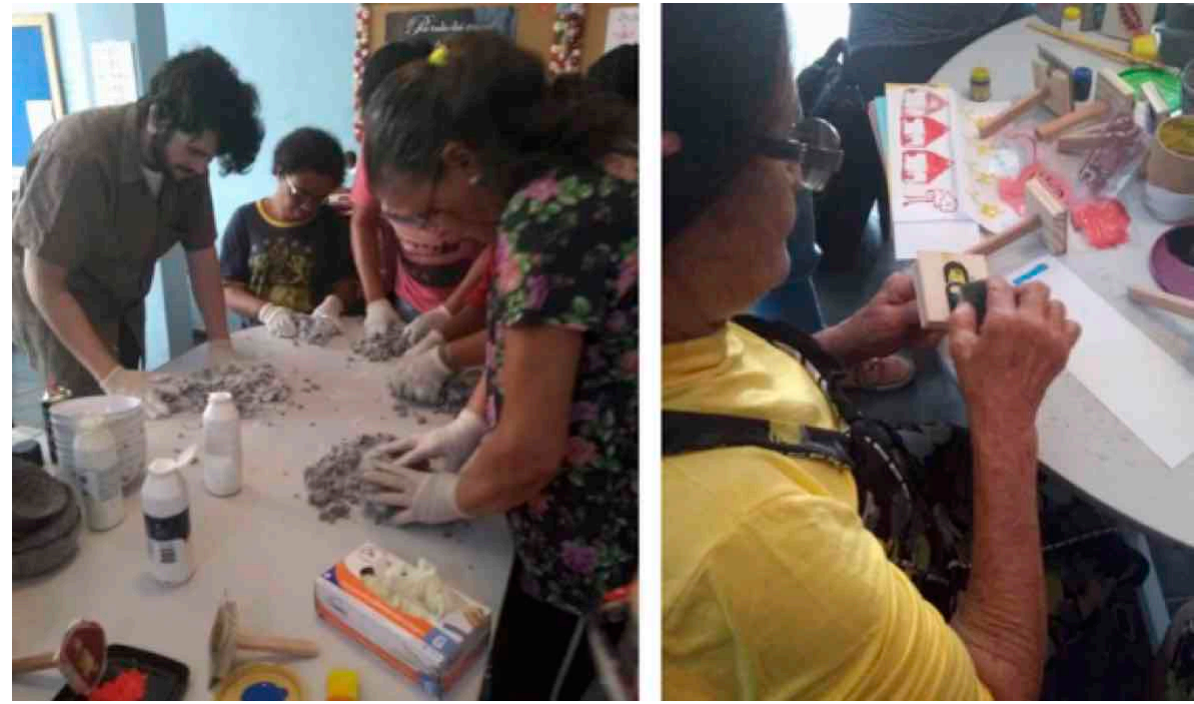

Fonte: Autor

O quinto e o sexto encontros foram destinados à produção das tigelas de papel machê, ao uso dos carimbos e à pintura.

Figura 7: Confecção das tigelas em papel machê no quinto e no sexto encontros

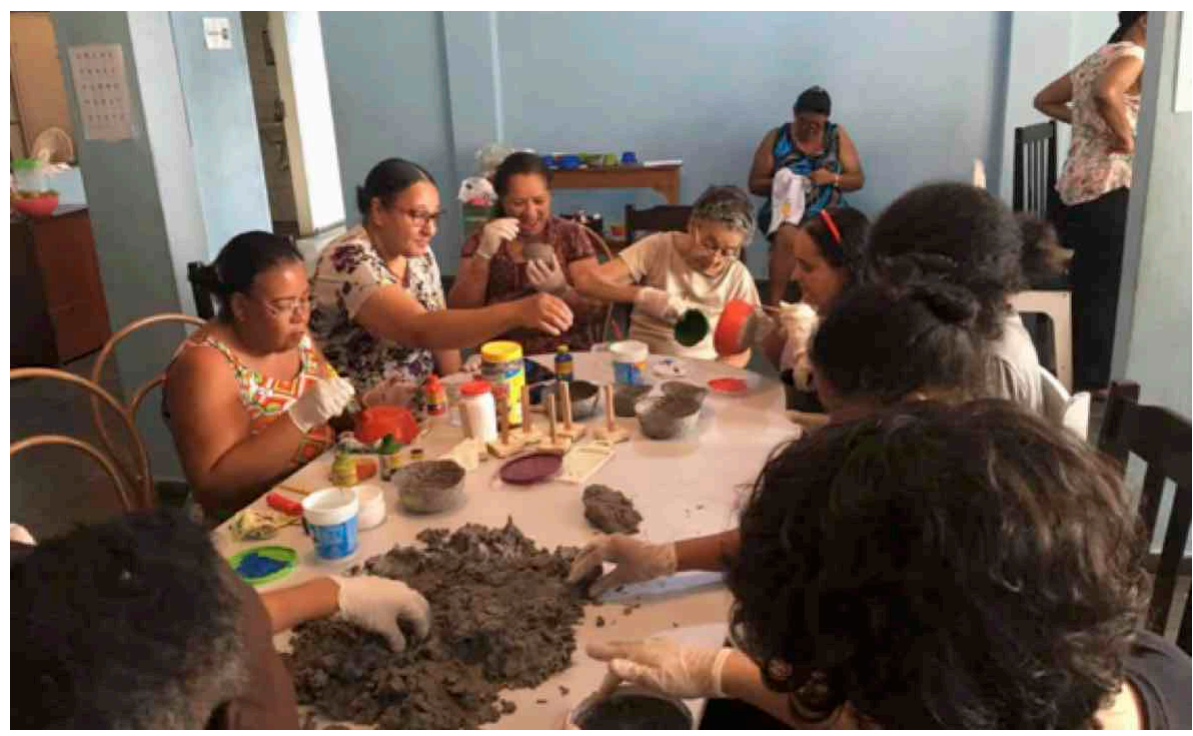

Fonte: Autor

Ao fazer os carimbos, a partir dos desenhos, as mulheres tiveram dificuldade porque os traços estavam muito finos. Diante disso, foi preciso alterar os desenhos, de modo a se ter maior preenchimento de tinta (Figura 8). 
Figura 8: Alteração no contorno dos desenhos dos carimbos, para facilitar a aplicação

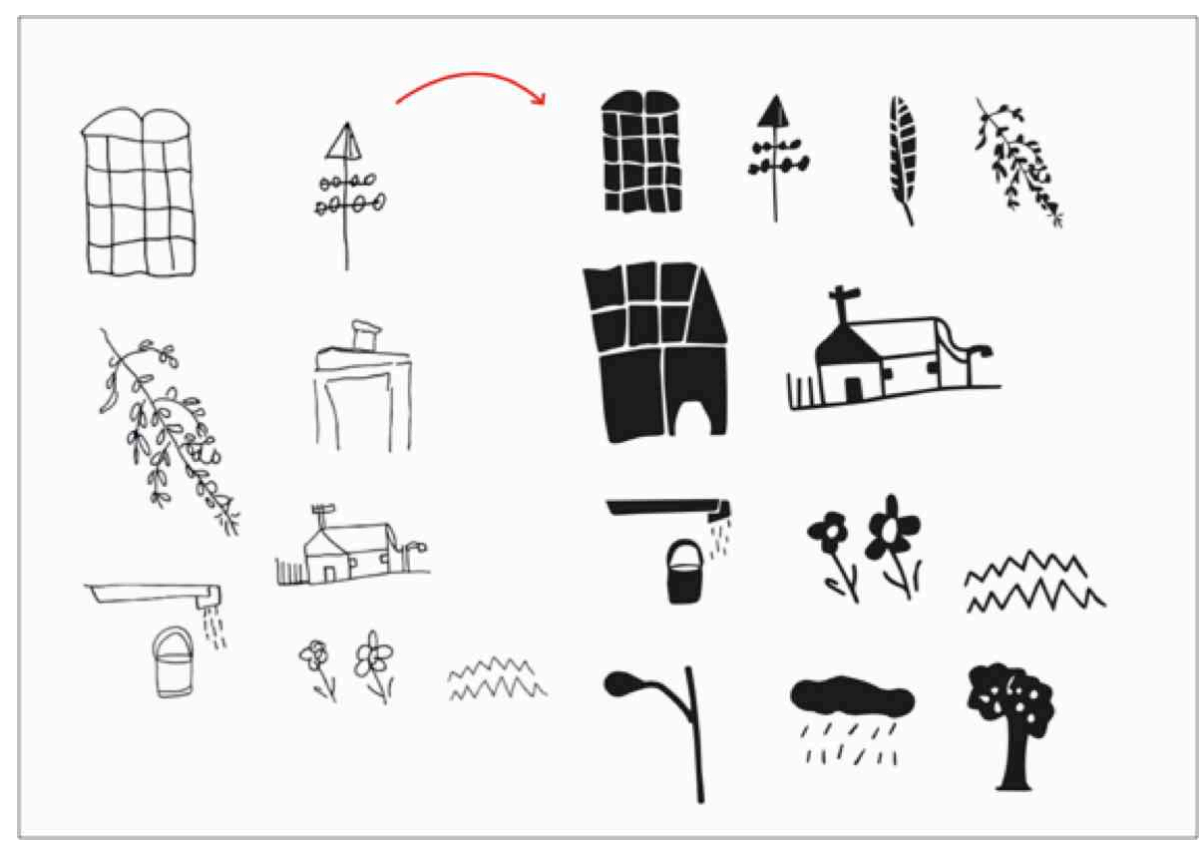

Fonte: Autor

Figura 9: Experimentação e aplicação dos carimbos
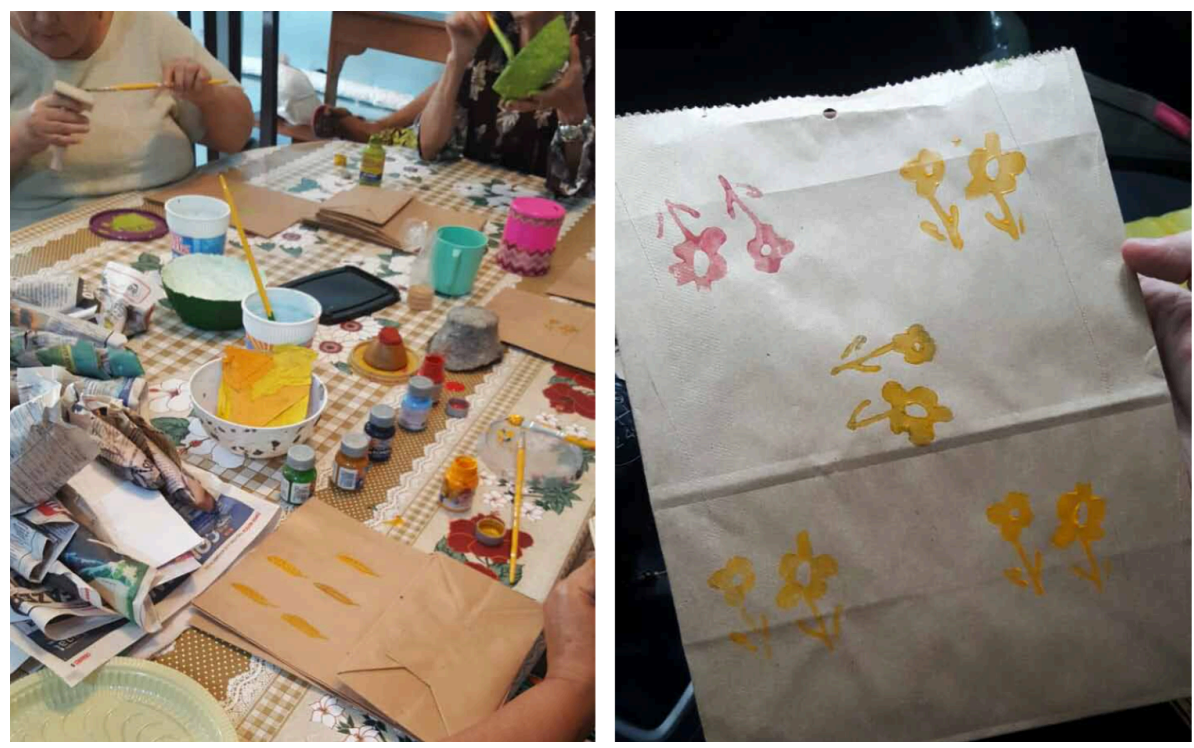

Fonte: Autor

A partir dos desenhos, diversas alternativas para padrões de desenhos foram desenvolvidas (Figura 10 e Figura 11). 


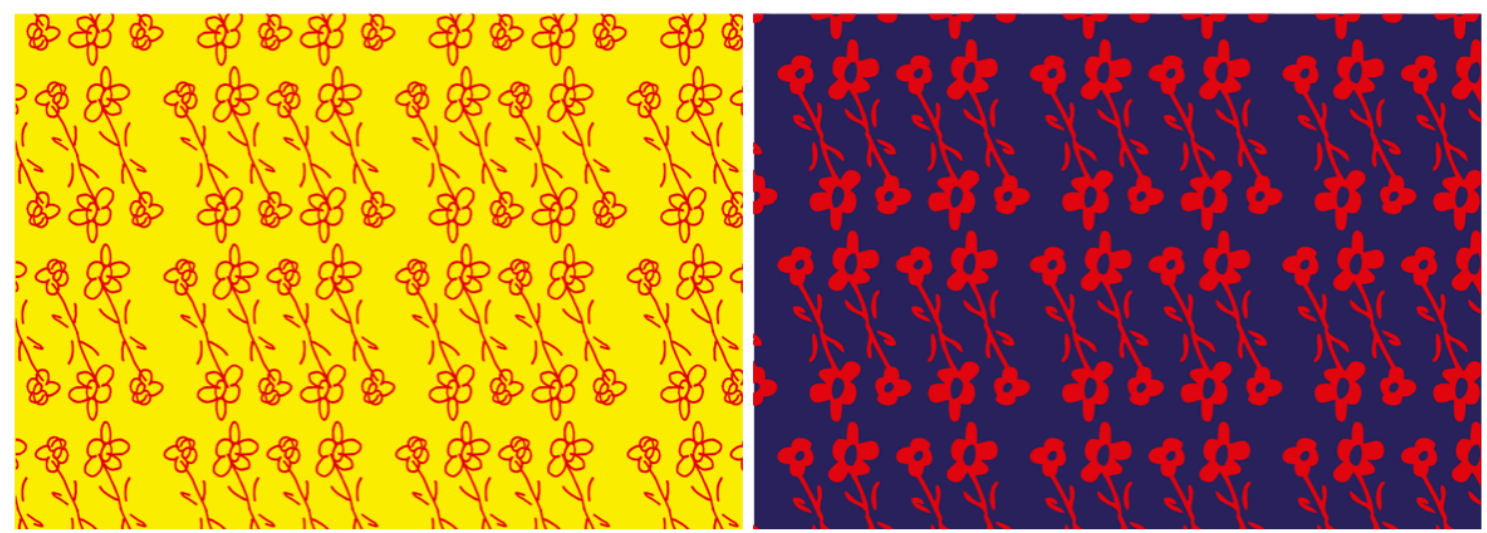

Fonte: Autor

Figura 11: Mais alternativas de aplicação dos desenhos com os carimbos
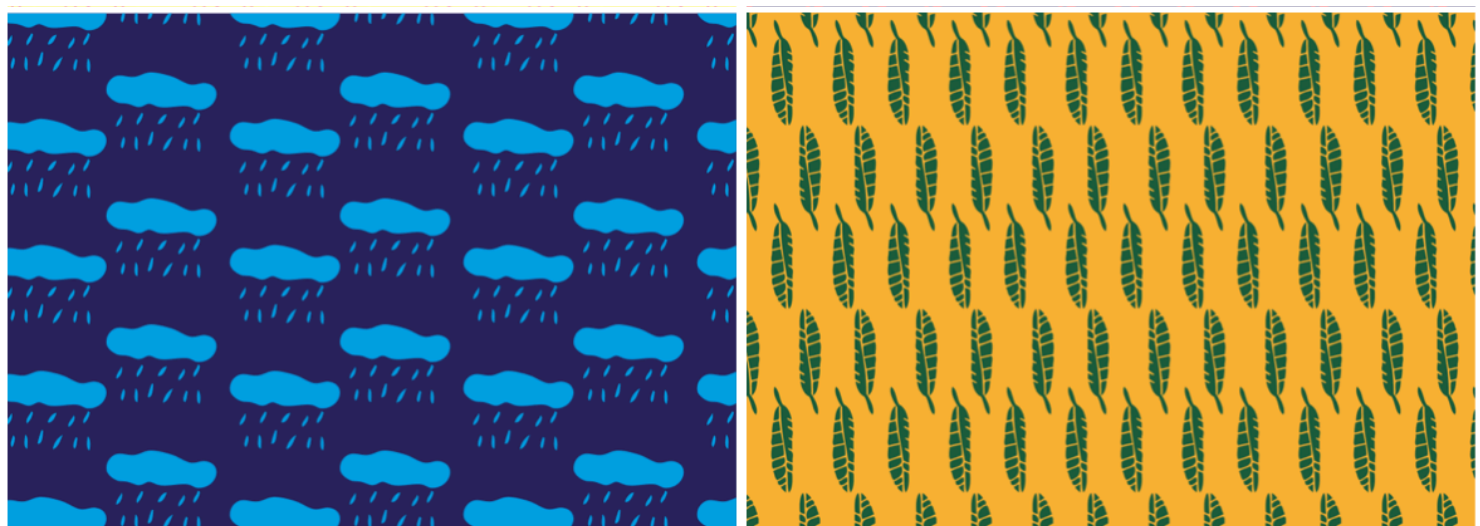

Fonte: Autor

\section{Manual de técnicas}

Este manual foi desenvolvido para reunir tanto as técnicas já aplicadas no Flores do Morro (pintura e bordado) quanto as novas técnicas de artesanato propostas pelos alunos: estêncil, carimbo e papel machê. O objetivo foi proporcionar autonomia às participantes do grupo, para que pudessem desenvolver as atividades de que mais gostassem, sem a necessidade de terem sempre um instrutor, que, na maioria das vezes, realiza trabalho voluntário com o grupo.

Durante o desenvolvimento do manual, as mulheres do Flores Morro participaram e se envolveram ativamente com as atividades, sugerindo alterações e maneiras de demostrar os principais passos para a aplicação das técnicas. As figuras 12, 13 e 14 ilustram a construção do manual. 
Figura 12: Manual de técnica para o estêncil

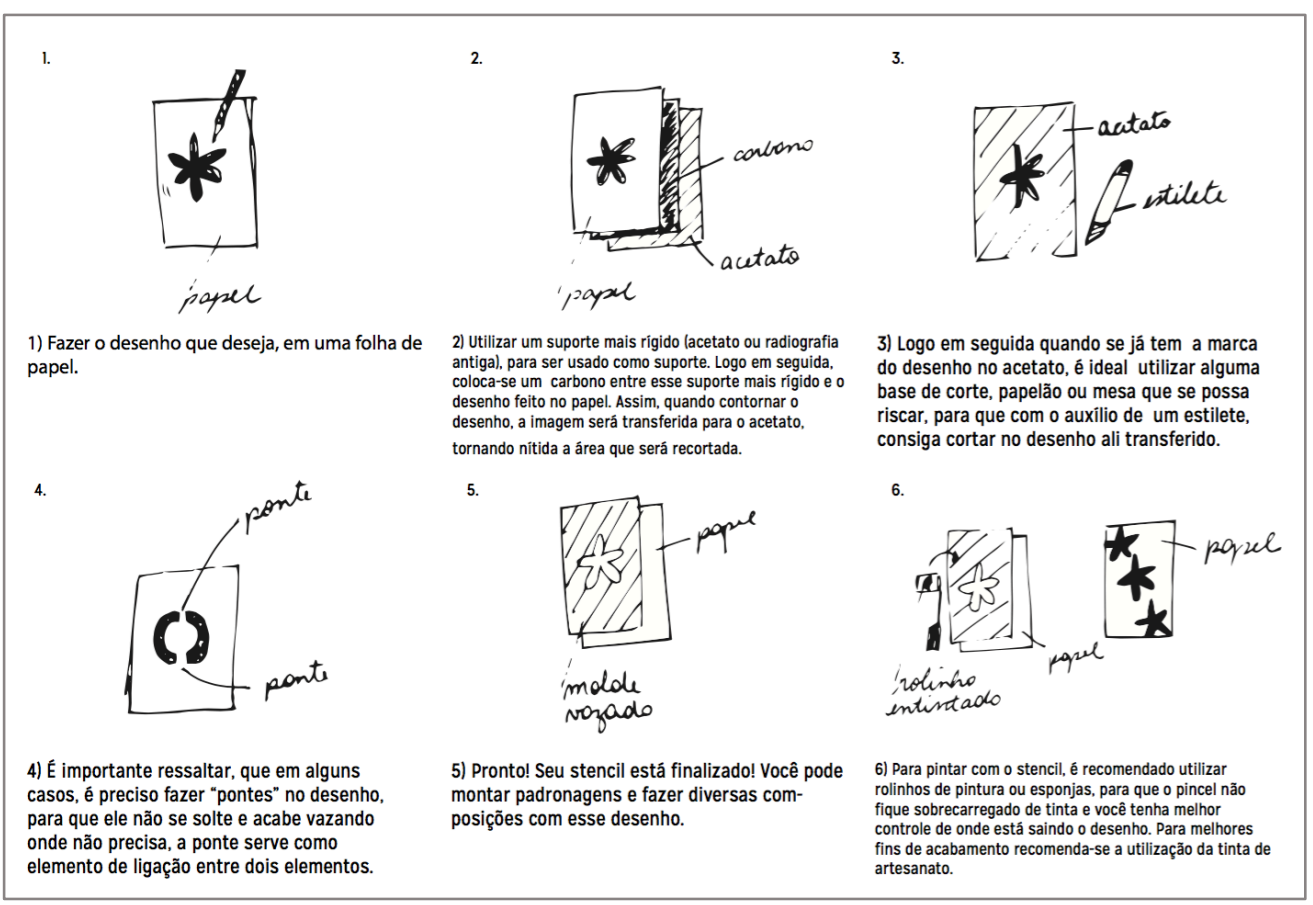

Fonte: Autor

Figura 13: Manual de técnica para o carimbo

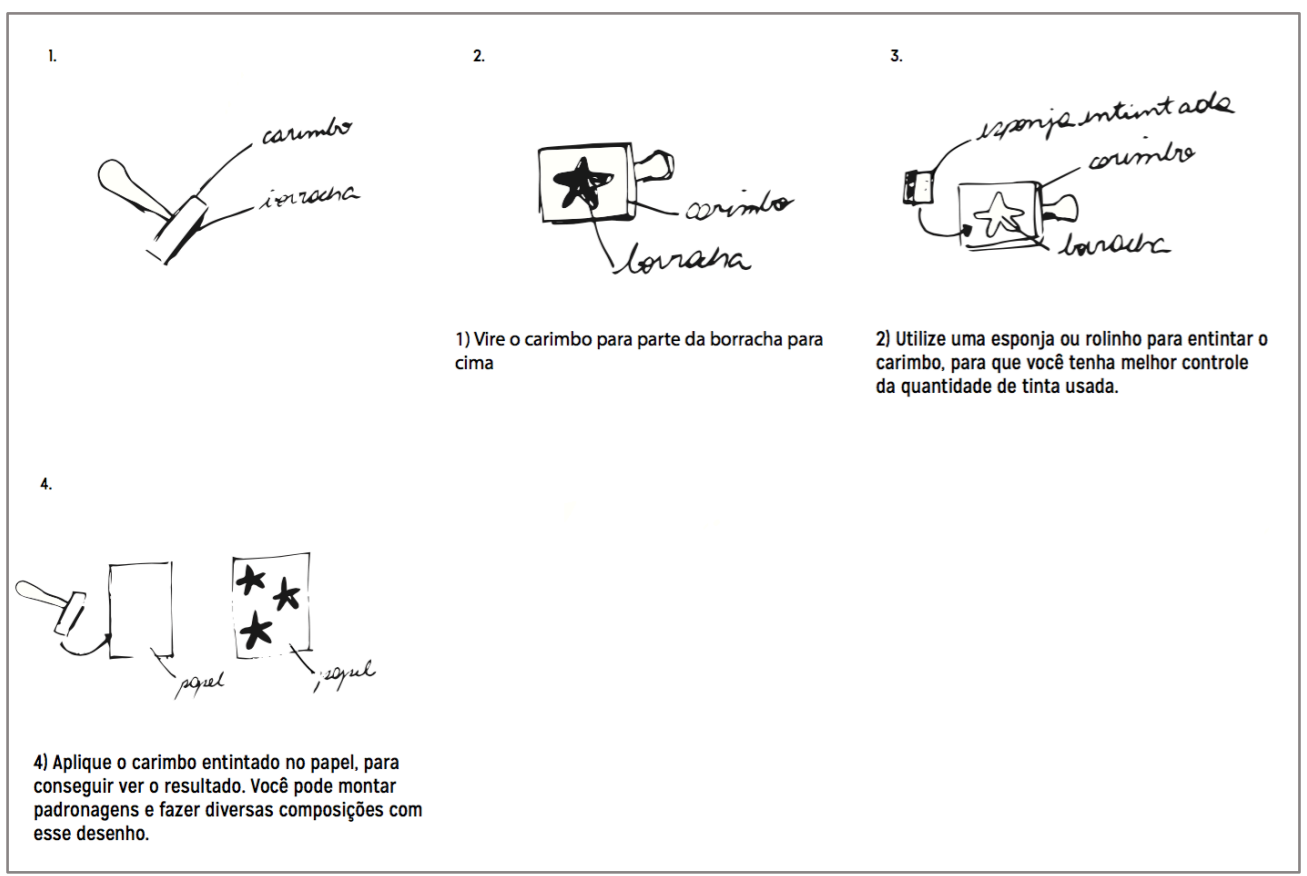

Fonte: Autor 
Figura 14: Parte do manual de técnica para o papel machê

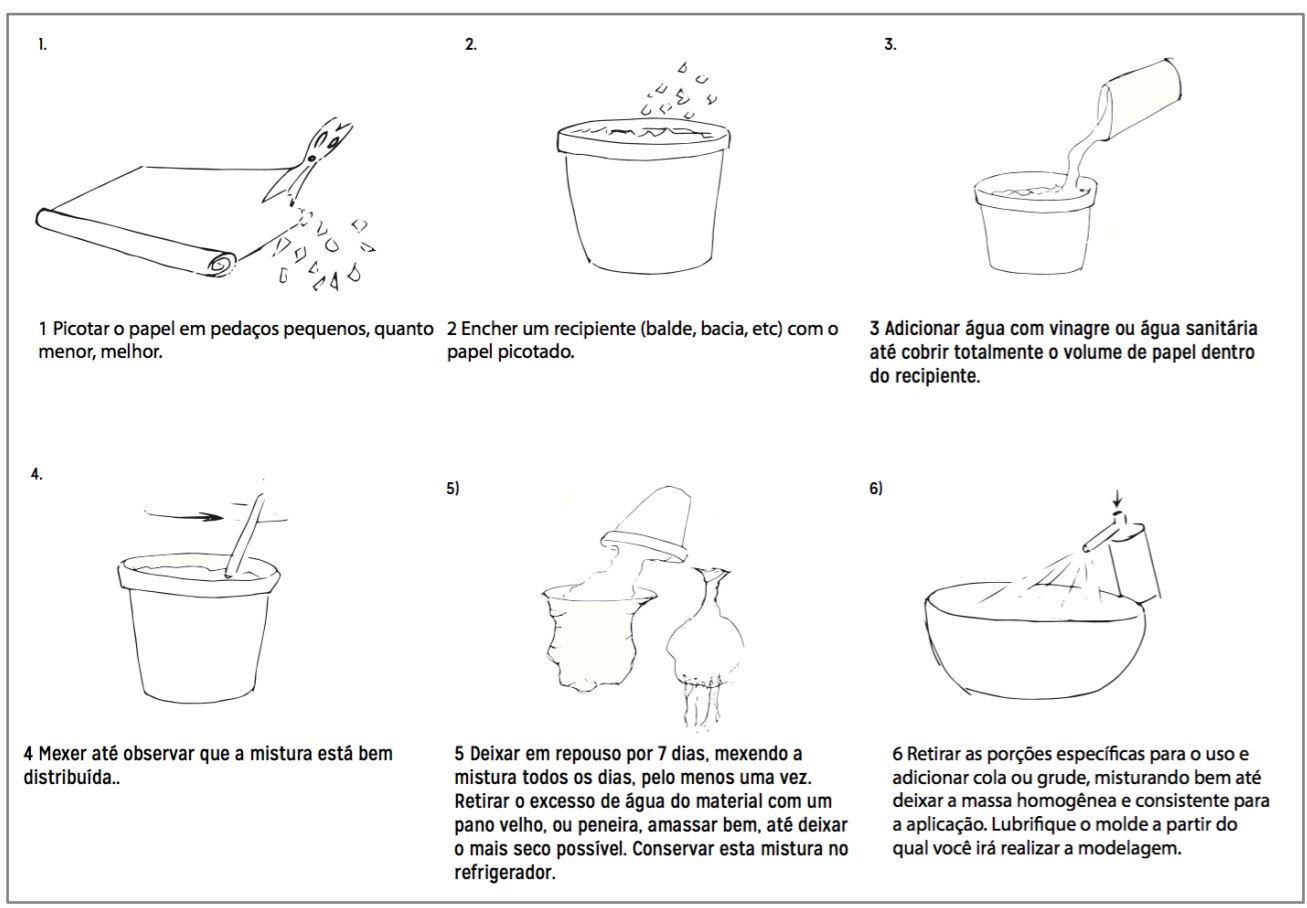

Fonte: Autor

Os manuais de aplicação da marca e de técnicas foram entregues impressos ao grupo Flores do Morro no final dos trabalhos.

Os alunos deste grupo conseguiram desenvolver uma abordagem com as participantes do Flores do Morro, por meio de uma comunicação horizontal, o que gerou empatia em todos os envolvidos. As pessoas da comunidade (participantes do grupo) puderam contribuir com seu saber, o que possibilitou criar caminhos de trocas. O depoimento de uma das mulheres do grupo sobre esta ação dá uma mostra da importância desse trabalho: "Esse movimento da universidade com a comunidade dignifica e nos faz sentir gente. Muitas vezes, eu me senti invisível para as pessoas, e esse trabalho nos estimulou a viver".

Um representante da Asmare e treze pessoas do grupo Flores do Morro participaram ativamente das apresentações dos projetos ao final da disciplina, fazendo comentários e contribuindo para o processo de avaliação dos trabalhos.

\section{Algumas reflexões e considerações finais}

A ação social da Cáritas no Morro das Pedras com o grupo Flores do Morro estava em risco de extinção. Essa ação de design contribuiu para fortalecer e estimular os encontros desse grupo de mulheres, bem como para apresentar novas oportunidades de ação e sustentação do projeto 
com esse grupo.

A disciplina proporcionou a experimentação e aproximação dos alunos com um contexto real, a partir da compreensão das necessidades, dos problemas e dos desejos das pessoas dos grupos, o que promoveu estímulo e engajamento na proposição das soluções de design. Verbalizou uma professora que acompanhou parte do processo: "Esse tipo de experimentação e imersão abre janelas para o aprendizado prático do design em contextos sociais e promove novas vivências para um processo de aprendizagem orientado para a autonomia, elemento sine qua non para a formação de novos designers" (informação verbal). ${ }^{3}$

Pode-se afirmar que os objetivos propostos pela disciplina foram atingidos. Os depoimentos dos alunos, ao final, de que gostaram da experiência e que não tinham tido até então contato com essa abordagem do design - neste caso, Design Social - demonstram isso.

Durante as orientações, não foram exigidos modos, maneiras ou métodos específicos para que os alunos seguissem. Pelo contrário, o objetivo foi dar liberdade e autonomia para que resolvessem os problemas de acordo com as decisões do grupo e dos envolvidos e pudessem aplicar o que estavam aprendendo em outras disciplinas. De certo modo, essa liberdade foi positiva, porque os alunos puderam tomar suas próprias decisões e escolher os caminhos para o desenvolvimento dos projetos. Por outro lado, nem todos os grupos tiveram orientações todas as semanas e em alguns casos o projeto não teve tanto êxito quanto ao apresentado em detalhe.

Outra constatação é que há necessidade de maior tempo para as atividades de disciplinas como essa. As duas horas semanais foram poucas para orientação de todos os grupos. Para as próximas, talvez o ideal seja uma carga horária de 45 ou de 60 horas / aula.

O melhor resultado foi ter percebido a felicidade, principalmente, das mulheres do Flores do Morro no dia de apresentação dos projetos. O simples fato de terem participado da aula alugamos uma van para o transporte delas até a Escola de Arquitetura da UFMG - fez com que se sentissem importantes e valorizadas, de acordo com os relatos delas.

Essa ação da disciplina reanimou as atividades tanto do grupo Flores do Morro quanto dos catadores da Asmare e nos fez sentir a importância de fazermos o bem para as pessoas e de ressaltar a responsabilidade de estarmos em uma universidade pública e, por isso, de firmarmos nosso compromisso com a sociedade. Sobretudo, fez com que percebêssemos que essa pequena ação melhorou a autoestima das pessoas que participaram das atividades da disciplina.

\section{Referências}

ARAÚJO, Renata Matos Eyer de. Um olhar sobre o Design Social e a prática do design em parceria. Ecovisões Projetuais: pesquisas em design e sustentabilidade no Brasil (livro eletrônico). Organizadores: Alfredo Jeferson de Oliveira, Carlo Franzato e Chiara Del Gaudio. São Paulo: Blucher, 2017.

BERGMANN, Márcia; MAGALHÃES, Cláudio. Do desenho industrial ao design social: políticas públicas para a diversidade cultural como objeto de design Estudos em Design | Revista (online).

\footnotetext{
${ }^{3}$ Relato da professora Sâmela Pessoa, da Escola de Design da Universidade do Estado de Minas Gerais, que acompanhou grande parte das atividades da disciplina.
} 
Rio de Janeiro: v. 25, n. 1, p. 51 - 64, 2017.

BONSIEPE, Gui. Tendências e antitendências no design industrial. Cadernos de Estudos Avançados em Design - Design e Humanismo. Barbacena: EdUEMG, 2013.

CELASCHI, Flaviano; MORAES, Dijon de. Futuro, bem-estar, interdependência: palavras-chave para o design contemporâneo. Cadernos de Estudos Avançados em Design - Design e Humanismo. Barbacena: EdUEMG, 2013.

COSTA, Mario Bestteti. Contribuições do design social: como o design pode atuar para o desenvolvimento econômico de comunidades produtivas de baixa renda. In: Anais do $2^{\circ}$ Simpósio Brasileiro de Design Sustentável (II SBDS) Jofre Silva, Mônica Moura \& Aguinaldo dos Santos (orgs.) Rede Brasil de Design Sustentável - RBDS São Paulo | Brasil | 2009.

HIDALGO, María. Diseño aplicado a iniciativas de Emprendimiento Social. Disponível em: http://www.emotools.com/media/upload/2012/12/11/articulo_diseno_social.pdf

KIMBELL, Lucy; JULIER, Joe. The social design methods menu. Fieldstudio Ltd: London, United Kingdom, 2012. Disponível em:

<http://www.lucykimbell.com/stuff/Fieldstudio_SocialDesignMethodsMenu.pdf

MARGOLIN, Victor; MARGOLIN, Sylvia. Um "modelo social” de design: questões de prática e pesquisa. Revista Design em Foco, julho-dezembro, vol. I, número 001. Universidade do Estado da Bahia. Salvador, Brasil. pp. 43-48, 2004.

SILVA, Anna Lúcia dos Santos Vieira e; OLIVEIRA, Emilio Augusto Gomes de; SOUSA, Carlos Eugênio Moreira de; MACAMBIRA, Filipe Garcia; JOSINO, Lara Dias Monteiro; ARAÚJO, Vitor Vieira. Dispositivos estratégicos de design social em processos de construção de identidade local. $p$. 2949-2961 . In: Anais do 12을 Congresso Brasileiro de Pesquisa e Desenvolvimento em Design [= Blucher Design Proceedings, v. 9, n. 2]. São Paulo: Blucher, 2016. 